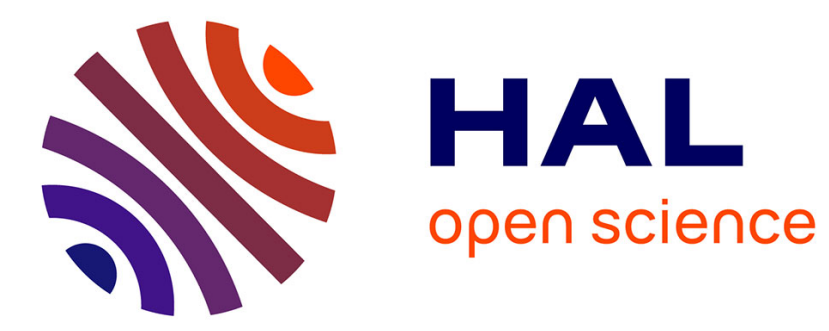

\title{
Naturalistic decision-making in expert badminton players
}

Anne-Claire Macquet, Philippe Fleurance

\section{To cite this version:}

Anne-Claire Macquet, Philippe Fleurance. Naturalistic decision-making in expert badminton players. Ergonomics, 2007, 50 (9), pp.1433-1450. 10.1080/00140130701393452 . hal-01709227

\section{HAL Id: hal-01709227 https: / hal-insep.archives-ouvertes.fr/hal-01709227}

Submitted on 14 Feb 2018

HAL is a multi-disciplinary open access archive for the deposit and dissemination of scientific research documents, whether they are published or not. The documents may come from teaching and research institutions in France or abroad, or from public or private research centers.
L'archive ouverte pluridisciplinaire HAL, est destinée au dépôt et à la diffusion de documents scientifiques de niveau recherche, publiés ou non, émanant des établissements d'enseignement et de recherche français ou étrangers, des laboratoires publics ou privés. 
Naturalistic decision-making in expert badminton players

Authors :

A.C. MACQUET*† and P. FLEURANCE $†$

Affiliation :

†Institut National du Sport et de l'Education Physique, Paris, France

e-mail : anne-claire.macquet@insep.fr 
Naturalistic decision-making in expert badminton players 
Abstract

This paper reports on a study of naturalistic decision-making in expert badminton players. These decisions are frequently taken under time-pressured conditions, yet normally lead to successful performance. Two male badminton teams participated in this study. Selfconfrontation interviews were used to collect data. Inductive data analysis revealed three types of intentions during a rally: to maintain the rally; to take the advantage; and to finish the point. It also revealed eight types of decision taken in this situation: to ensure an action; to observe the opponent's response to an action; to realize a limited choice; to influence the opponent's decision; to put pressure on an opponent; to surprise the opponent; to reproduce an efficient action; and to play wide. A frequent decision was to put pressure on the opponent. Different information and knowledge was linked to specific decisions. The results are discussed in relation to research that has considered naturalistic decision-making.

Key words: Naturalistic decision-making; Expert performance; Badminton. 


\section{Introduction}

In the training domain, it is considered that athletes apply decision rules that are implemented during the training (e.g. French and McPherson 1999, McPherson and Kernodle 2003). This rules contain one or more conditions that involve a particular action ('if... then'), (e.g. Williams and David 1995). These ideas are supported by classical models of cognition. These models insist on information processes and knowledge bases (e.g. Chase and Simon 1973). This focus on information processes and knowledge bases has had two consequences: the former has focused on human functioning and the latter has assigned task concepts. In these models, the human system is compared to a computer-metaphor that processes information, handles knowledge and symbols, and relies on diagrams and algorithms. These models focus on quantitative parameters, such as reaction time, movement time or error (in comparison to a target). Therefore, the classical cognitive approach has used a mechanistic approach that determines that action is a direct result of cognition (Sanders 1986).

The human system contains a knowledge base gained from learning and experience, which is available for use to direct action. Therefore, an individual can be considered as a rational and omniscient actor who possesses all the useful knowledge required to act. According to rational decision-making models (e.g., Pitz 1992) individuals assess the usefulness of each possible response in order to maximize behaviour. It is proposed that one approach is optimal and corresponds to each situation; it belongs to an individual repertoire and contains rules and strategies that have to be learned and used advisedly. These strategies allow individuals to anticipate actions. They rely on knowledge, competencies and specific game analysis. According to this model an athlete's strategies are considered to be preregulated; they function like algorithms and result in a minimum number of errors (e.g., understanding error in a current situation, choice error or realization error). An athlete's 
expertise, which results from a hyper-adaptation to the task, limits realization error (Ericcson 1996), but they cannot avoid decision-making error or understanding error. Decision making, according to this model, seems not to be able to adapt to a current situation.

The second consequence focuses on task concepts. This has typically discredited the observable components of human behaviour and consequently has not taken into account its dynamic and evolutionary nature (De Keyser 2003). Observation of sporting situations has, therefore, lead to doubts concerning rational decision-making. Expert sports decisions do not allow for control over situations where the athlete is fully committed. Frequently, their control is limited; in the sport of badminton, it leads to a continuation of the rally but not to the ultimate success in winning it. Decisions can vary markedly between situations and can change considerably with experience, space, and biological constraints. One athlete may not make the same decision every time he/she encounters a similar situation. Similarly, decisions can vary between individuals. In these conditions, the validity of rationalistic decision making can be questioned to aid in the study of the heuristic impact of naturalistic decision-making models.

\section{Naturalistic decision-making}

\subsection{Natural situation}

In high-level sport performance analysis, it is sometimes difficult to define task components. For example, De Keyser (2003), states that the concept of 'task' does not appear sufficient to fully understand what is happening in any given situation. It does not take into consideration the context, or the individual who performs the task (with limits and work constraints). The 'situation' concept seems more appropriate to an understanding of individual activity during 
the course of action. Situations can be termed static (they evolve with individual activity) or dynamic (they evolve with non-individual factors).

Amalberti and Hoc (1998) have considered the situational context through the parameters of temporality, uncertainty and control. Temporality refers both to the available time to act and to the evolution of a part of the situation g.i.e., its process. Control can be partial or total. Uncertainty can be spatial, temporal or factual. In sport, these 'natural' situations consist of situations arising during coaching, training or competing. Research must, therefore, consider task contingency, as well as consideration of the continuous processes which are used in naturalistic situations. Naturalistic research uses a situation-action perspective (Suchman 1987), and focuses on how individuals match their activity to a particular context. Action is not regulated by an a priori plan.

Studies concerned with sport have focused on: the temporal components of coaches' actions (e.g., Sève and Durand 1999); the temporal and conceptual organization of interaction between coaches and athletes during competition (e.g., d'Arripe-Longueville et al. 2001); knowledge building during the course of an action (e.g., Sève et al. 2003); action organization according to athlete performance level (e.g., Hauw and Durand 2004); goal differentiation in consideration of competition type (e.g., Saury et al. 1997); and naturalistic decision-making (Macquet 2001). These studies considered opportunistic and situational cognition and focused on local decisions, considered in a diachronic and non-synchronic way. The selection of verbalized decisions depended upon their meaning for the athlete; decisions do not naturally follow one another over time. The present study aimed to highlight a synchronic and a diachronic issue. 


\subsection{Decision in natural situation}

Previous work in the area has considered emergency decision making in the domains of nuclear power, transportation, industrial management, military operations, and emergency services. These studies are relative to two approaches which are developed independently, but are nevertheless very similar. The model of Naturalistic Decision Making (e.g., Klein et al. 1993, Zsambok and Klein 1997) focuses on: ill-structured problems; dynamic and uncertain conditions; ill-defined and evolving goals; action and feed-back loops; temporal pressure; high risk situations; high numbers of individuals committed to a situation; and organizational standards. The model of sufficiency has been developed by Amalberti (1996, 2001), who examined ill-defined problems and dynamic problems. These models refers to decisionmaking. All the research above considers decisions which were adapted to the situation and the person. Adaptive decision-making allows control over part or all of a situation. In contrast to cognitive conceptions, adaptive decision-making is more satisfying for the individual and corresponds to actual individual competencies. Adaptive decision-making refers to the athletes' own goals for a situation in a specific context. Under these conditions, decisions do not seem rational, but do seem appropriate and sufficient for the decision-maker. This sufficiency is linked to limited capacities or to contingent rationality (Simon 1957). According to Amalberti and Malaterre (2001), an individual is not a passive agent of this rationality and organizes behaviour to cope cognitively. The athlete takes risks and proceeds by anticipation to reduce situational complexity. The athlete commits to a more autonomous level of behaving instead of a reflexive and logical process to save resources.

Naturalistic decision-making therefore focuses on a continual process in a natural situation. It takes into account task contingency. It considers both the situation arena (objective spatial and social environment), and the product of an activity setting, that part of 
environment marked by action, see Lave (1988). It is argued here that this framework will affect the continual process that is used in naturalistic situations.

\subsection{Decision-making process}

Unconditional, rational analysis concerning an action is not always possible or desirable. An individual may function in such a way so as to achieve an optimal cognitive working mode. In this case, optimal implies a situation of compromise, allowing goal(s) attainment in a dynamic way with appropriate and effective performance (Amalberti and Malaterre 2001). This concept suggests three ideas. The first conforms to a notion of sufficiency; it corresponds to a response that is adapted to the environment according to an individual's goals, knowledge and competence. An individual athlete cannot cognitively and consciously understand all actions and behaviours. Similarly, the athlete cannot physically perform all actions; an optimal response that is the product of these abilities must be produced. The second idea relates to the concept of dynamic adaptation. It comprises two aspects: attained performance level over time; and acceptable global performance level at any given moment (final result or local/intermediate result). The third idea refers to meta-knowledge. This concept considers the management of acceptable and accepted risks.

The notion of sufficiency (Amalberti 2001) considers the capability for understanding, decision-making, control and execution. These factors contribute to a global plan and activity emerges through environmental coupling and the use of natural affordances (Gibson 1979, Suchman 1987). This sufficiency framework therefore suggests a dynamic and contextual building of cognitive activities. It aims at a more effective response to situation evolution and according to limited individual resources (Amalberti and Hoc 1998, Hoc and Amalberti 1999). To manage complex and dynamic situations, it would not be ideal to have a solution 
that was completely predetermined (Amalberti 2003). Individuals require compromises to deal with situations presenting conflicting dimensions. Action must be opportunistic rather than rational. Decision-making should appear as a continual process that is coupled to the environment. It could be compared to a process of natural drift: decision-making would continue until it would no longer be satisfying for the individual to be committed to a situation. In these conditions, the individual would 'wait' for situation evolution, this would allow further understanding in a way sufficient to act. Behaviour would then proceed to risks limits that would represent an afforded zone (viz. the concept of meaningful as used by Gibson, 1979).

The research that has considered the decision making process shows two key stages. The first relates to situation assessment: the definition of the problem; awareness of risks; and of the time available. The second is the choice of a course of action that depends upon available situation possibilities. In consideration of these stages, Hollnagel (1998) has proposed concern for the cyclic character of human cognition and on the difference between observation and inference. In his context control model, Hollnagel hypothesizes that human performance is the result of a controlled use of competencies according to a situation not the result of response sequences that are predetermined by events. The control can be described in reference to a continuum, going from no or limited control over events, to complete control. Hollnagel (1998) proposed four modes of control: scrambled control; opportunistic control; tactical control; and strategic control. In scrambled control, the choice of action is unpredictable or haphazard. The individual does not consciously think, or thinks only a little about what to do. This mode appears when task demands are high, when the situation changes in an unexpected way, when it is unfamiliar, or when there is a loss of situational awareness. The extreme case of scrambled control is a panic situation. Opportunistic control involves action that is determined by the salient features of the environment, instead of more stable 
intentions or goals. There is little planning or anticipating, because context is not clearly understood or because time pressure is high. Individual behaviour is lead by perception of the interface of dominant features, experience, and habits. In tactical control, behaviour is based on planning and on the use of rules or known procedures. The latter is limited to a particular context. If planning is often used, then performance refers to rule-based behaviour. In strategic control, the individual takes into consideration the global situation, according to long term goals. This mode is predicted to lead to more efficient performance and is influenced by knowledge and skills. The person, such as a high-level athlete, moves from one control mode to another depending on the perceived characteristics of the situation. In order to predict the expected level of performance, it seems important to know how actions are chosen and subsequently performed.

\subsection{Decision and coordination}

This review has focused on research that has used motor function limited to movement of handles and joysticks or the press of button. There is a limited amount of research that has considered some of the over-learned, highly coordinated skills that are present in high-level sport. In these studies, coordination will have little influence on decision-making. According to Hollnagel's model (1998), elite sport behaviour corresponds only to the tactical control mode, opportunistic mode, or strategic mode. Coordination can, therefore, affect decisionmaking if the athlete is involved in an unfamiliar situation and if coordination is not adapted to the situation. In this case, the athlete has to create a new coordination pattern and use scrambled control.

This study aimed to determine how high-level performers make decisions during the course of an action. Decision-making was studying in a synchronic and in a diachronic way. 
The research also considered decision-making within the temporal constraints of the match to reveal any similarities and differences between situations and to understand features structuring decision-making.

\section{Method}

\subsection{Participants}

Four male expert badminton players participated to this study. All were ranked in the top 23 players in the world at the moment of the competitions. They completed a written informed consent form prior to participating in the experiment and the study was approved by the local ethics committee.

\subsection{Data collection}

Two types of qualitative data were collected: data observed and recorded during competitive matches; and data elicited during self-confrontation interviews.

3.2.1. Data observed and recorded during the competitive matches. Two matches were recorded from international qualifying tournaments for the Athens 2004 Olympic Games. A digital video camera was placed within the stands of the court, in the middle of the court's width. The researcher noted other forms of data that were considered important for the research and were not recorded directly by the camera.

3.2.2. Data collected during self-confrontation interview. Verbal feedback was collected after each competition during the self-confrontation interview. These were conducted with both team players. The self-confrontation interview is a method developed by Von Cranach 
and Harré (1982). It aims to elicit ongoing cognitions. The athlete is presented with their activity as soon as possible after the recording. Players were asked to describe and explain their own behaviour and activity. The duration of each interview was limited to 150 minutes. Experienced coaches proposed that the first four actions were judged the most significant in the course of the rally, since they typically determined the outcome of the rally. Therefore, players had to explain the decisions behind the first four actions of each rally. These choices were constrained by the available time for the interview. Only the first two sets were retained because of time constraints (badminton players have to win two sets to win the match). The interviews were conducted during two periods to avoid tiredness and loss of concentration. Each period covered one set. Interviews took place during the third and the fifth day after the match for Team 1 and during the match day and third day after the match for Team 2. Players could stop the video at any time to ask questions. Interviewer questions were concerned with specific actions and sought to avoid general answers. For example, a participant might be asked "what do you want to do here?" or "what did you see here?" "what were you thinking about there?". Questions were limited to decision-making; they did not attempt to cover the participants' perceptions regarding the ultimate success of their decisions.

\subsection{Data processing.}

The interviews were transcribed verbatim and provided for the participants to confirm the validity of transcription. The transcripts were analyzed through a process of inductive analysis containing three phases: identification of extrinsic data (score, description of the situation) and intrinsic data (short accounts of decision, perceptions and knowledge used in decision making); labelling decisions (the situation referred to) and intentions (attributable to the rally); labelling perceptions and knowledge. The coding reliability procedure was assessed by 
two independent researchers in sport ergonomics. The intentions and decisions labels were judged by two coaches.

\section{Results}

Qualitative analysis produced 312 short accounts (145 for Team 1 and 167 for Team 2). Decisions and subsequent intentions, features that structured decision-making and decisionmaking efficiency related to behaviour and action were analyzed.

\subsection{Players' decisions and subsequent intentions during the rally}

Local decisions (defined as the course of action) and intentions (attributed to the progression of the rally) were labelled. Three types of intentions were identified: 'to maintain the rally'; 'to take an advantage to build the rally'; and 'to finish the point'. Eight types of decisions were elicited. The sub-category 'to maintain the rally' incorporated decisions such: to ensure his action; to observe the opponent response to his own action; to realize a limited choice. The intention 'to take an advantage to build the rally' referred to influence opponent decision; to put pressure on opponents; to surprise opponents; to reproduce an efficient action; and to play wide.

Intentions and decisions labelling can be explained through the players' verbal responses. Intention to maintain the rally meant that the player wanted to continue or engage in the rally, he aimed to delay any attack but he did not want to lose the point. The decision to ensure his action signified a neutral action, the player did not want to take any risk with the shot. For example: "I aimed to produce a classical serve" (match 1, set 1, decision 75). The decision to observe an opponent response to his action meant the player aimed to test the 
opponent's abilities. In another example the decision was, "to produce a short serve and observe the return" (match 1, set 1, decision 9). The decision to realize a limited a choice meant decision-making was made under pressure to keep the rally going, "I hadn't any other choice than to do a high lift' (match 2, set 2, decision, 27).

The intention to take advantage to build the rally meant that the player tried to go on the attack, to be in a good position to finish the point later in the rally. The decision to influence the opponent's decision was intended to guide the opponent's action in a particular way or to dissuade the opponent from making a specific action later in the rally. In a further example a player referred to an action, "to take the attack by playing under the tape to make them to lift the shuttle" (match 2, set 2, decision 32). The decision to put pressure on the opponents intended to increase the shuttle's speed and accuracy and players used terms such as to, "block at net to take the attack" (match 1, set 2, decision 15). For the decision to surprise opponents the behaviour was designed to create an unexpected trajectory for the opponent and led to phrases such as to "cross my serve to surprise him" (match 1, set 2, decision 21). Reproducing an efficient action referred to a previous effective action and players commented "to serve by doing my best" (match 2, set 2, decision 48). By playing wide, the players intended to shoot along alleys or the back of the court. In describing these conditions, players used phrases such as, "play wide by shooting in the alley" (match 1, set 1, decision 2).

The intention to finish the point referred to winning the rally by playing with speed and accuracy. For example, players commented that they should, "finish the point by shooting to half-court with the most powerful and steepest trajectory possible" (match 1, set 1, decision 55). This intention refers to both the current and a future situation because the intended result was to change the situation and finish the rally. 
Analysis of the players' intentions revealed that the players often intended to take advantage to build the rally (Figure 2). Analysis of decisions revealed similarities between players. For example, the three most frequent decisions were: to put pressure on opponents; to surprise opponents; and to influence opponent's decision. However, decisions concerning observing or ensuring an action were seldom made.

For Team 1, decisions were more varied in the first set than in the second set. For Team 2, there were fewer differences between the sets. Results suggested that, at first, Team 1 altered their game to test their opponents, and to gain an understanding of their play. They then moved to decision-making that was more focused on the outcome of the rally. Team 2 tried to impose their style of game on their opponents and as long as their decisions appeared effective they continued with this style. When they became less effective they found other solutions to finish the rally (from decision 30 after 5 min play for set 1 ; and from decision 20 after 3'19 play for set 2). Team 2 did not aim to observe opponent's reactions to their actions. A particular local decision, in situation, corresponded to several categories of decision. For example, a straight clear was used with the aim of realizing a limited choice; to produce an efficient action to play wide and to influence the opponent's action.

'[insert figure 1 about here]'

\subsection{Decision- making in prototypical situations}

A number of typical situations were observed. These were serve, return of serve and third or fourth shot. Analysis of decision-making in prototypical situations revealed similarities and differences. These are discussed below.

4.2.1. Serve. Results, shown in Figure 3, indicated a predominance of intention to build an advantage in the rally. The most frequent decision was concerned with attempting to surprise 
opponents. This was more frequent for Team 1 than Team 2, and more frequent in the second set than in the first set for both of teams. A further trend revealed two decisions: to reproduce an efficient action and to influence the opponent's decision. Decisions were more varied for the first set for Team 1, and for the second set for Team 2.

'[insert figure 2 about here]'

4.2.2. Return of serve. The results, shown in Figure 4, indicated the players' intention to build an advantage. The most common decision was to put pressure on the opponents. This was more frequent in the first set than in the second for both teams. Decisions were more varied for Team 2 than for Team 1. They also achieved more returns. Team 2 tried to finish the rally and to influence and to surprise their opponents. They were more varied in the first set than in the second set. Team 1, essentially, aimed to put pressure on their opponents. '[insert figure 3 about here]'

4.2.3. Third or fourth shot. Figure 5 highlights the player's attempts to build an advantage. The second intention varied between teams. Team 1 aimed to maintain the rally, whereas Team 2 intended to finish the point. The most common decision was to put pressure on the opponents. This trend was more pronounced in the second set for Team 1. For Team 2 it was more marked in the first set. In addition, differences were observed between other trends. For example, Team 1 attempted to realize a limited choice for their opponents, especially during the second part of the first set. They also aimed to keep play wide. Team 2 aimed to surprise their opponents, and also to realize a limited choice. The decisions of Team 2, therefore, showed greater difference.

'[insert figure 4 about here]' 


\subsection{The structured components of decision making}

Inductive analysis of the transcripts highlighted two categories; information and knowledge. These can be subdivided into eleven sub-categories. The sub-category 'information' incorporated: player's actions and position; partner's actions and position; opponent's action and position; and the shuttle trajectory. Knowledge referred to the player's abilities, behaviours, efficiency in action and trust; to the partner's abilities; and to the opponent's abilities (e.g., "he always serve to the same place" match 1, set 1, decision 36). Knowledge also pertained to the individual and collective or situational rules (e.g., "the only way to stay in the rally is to lift" match 1 , set 1 , decision 5). In addition, a preceding event was also included in the sub-section 'knowledge'(e.g., "it's the same situation as before", match 2, set 2, decision 87), as was expectation about the opponent's action (e.g., "I expected a serve to the T position", match 2 , set 1 , decision 1 ), and consequences of the player's actions (e.g., "it leads to move the player away from the net and causes the back player to have to lift and give the attack back" match 1, set 1, decision 38).

The most frequent associations were found to be between decisions and some structured components of decision-making. No evidence was found for rare or infrequently made decisions. Sometimes, there were differences between teams. The decision to ensure his action was rarely taken by Team 1 . However, Team 2 required information about the player and his opponents. In the case of the decision to observe the opponent's response to his own action, Team 1 often reported rules (especially individual-based rules). Whilst in relation to realizing a limited choice, the large majority of information referred to the player himself, with knowledge concerning rules about a situation (e.g., "I am in late, my only solution is..."). 
To influence the opponent's decisions, the majority of responses were directed at the opponents; they concerned knowledge for Team 1 and information for Team 2. Fewer responses referred to the consequences of actions for Team 1, and (collective) rules for Team 2. The decision to put pressure on the opponent was indicated by information associated with the player and his opponents and the majority of knowledge was assigned to expectations. Knowledge concerning consequences and collective rules was often reported by Team 1, but not by Team 2. In order to surprise opponents, the decisions revealed a large amount of information relating to opponents and knowledge concerning expectations. Team 1 also verbalized knowledge about a preceding event, whereas this was seldom the case for Team 2. In justifying their decision to reproduce an efficient action, Team 1 often reported knowledge about individual rules, whereas Team 2 referred to previous events or to a player. With reference to playing wide, much information was attributed to the player and his opponents. Team 2 frequently reported decisions relating to shuttlecock trajectory, unlike Team 1. Decisions regarding finishing the point were linked to information concerning the player and his opponents.

\section{Discussion}

The results of this study showed that players did not try to immediately win a rally. In most cases they created the optimal conditions to end it successfully. The findings will be discussed from three perspectives: the situational understanding for building the rally; the contextual building of the rally; and the implications for coaching.

\subsection{Situational understanding to build the rally}


The results showed that situational understanding was progressive. It depended on the available information at different times in the rally (e.g., position, behaviour of the players, shuttle trajectory). This ability to quickly take account of evolving features of the situation corresponds well with the concept of situation awareness (Wickens 1992, Endsley 1995, Endsley et al. 2003). The environment is continuously assessed with the aim of including this information in the player's actions. Understanding appeared to be dynamic and contextual. It was linked to uncertainty about the environmental evolution. The player tried to understand the situation. When this understanding seemed sufficient for the player to act, he made a decision whilst still continuing to assess the environment. The situation was considered through the coupling between himself and all other players. Players showed that they had a shared knowledge and understanding of each other's competencies and they took account of these features for decision-making. Decisions related to realizing a limited choice, putting pressure on an opponent, or observing an opponent's response to his action showed a shared knowledge and understanding between partners. Decisions related to surprising opponents were linked to a previous event or to expectations about the opponent's action. Shared knowledge and competencies correspond to a common frame of reference (Hoc 2001) which takes account of prescriptive data available from the players' behaviours and actions. It anticipates changes according to the player's own features (e.g., competencies, knowledge) and situations (e.g., specific previous situations either practiced or observed). The frame of reference can also evolve according to significant events (e.g., earlier situations, player competencies). A change of decision during on-going play suggests that the reference values evolve from one momentary situation assessment to another. The reference value for a future situation is not a random fluctuation around a constant, predetermined strategy. Instead it depends on an antecedent reference value; the successive situational assessments created from the player's experience. The decision does not seem to depend on a constant component of the 
studied system, such as a personality or predetermined strategies. These findings are consistent with those obtained for decision-making situations in volleyball (Macquet 2001). In the volleyball study players employed knowledge of current and previous matches, concerning teammate and opponents competencies, with the aim of increasing the competition.

Analysis of the intentions and decisions in the present study revealed the players took account of various time-based factors: situation; rally; and set. Intentions were primarily concerned with issue relating to the rally and set. Whereas, decisions were strongly linked to situation control. Knowledge categories showed an emphasis on these time-based issues too. For example, players took account of past events, current player competencies and rules, and anticipated future expectations and action consequences. The use of various temporal-based decisions is consistent with results found in a volleyball context (Macquet 2001), where decision and intention categories were found to be similar to the present study. Decisionmaking clearly depends on previous, current and anticipated future events. The reference to past events is also consistent with data from the sport of table tennis (Sève et al. 2003). In the process of decision-making, players use knowledge that has been built up during the match and/or earlier matches. They make links between current and past situations to produce an efficient decision for any given moment.

Player's assessments of the situations exhibited differences in understanding. Some situations were poorly understood, or were understood too late (because of the unexpected evolution of the current situation). In these cases, the player tried to adapt by also performing unexpectedly. Where the situation had a higher time length (e.g., the serve), situational assessment was easier. In all cases, the player did not seem to reach a complete understanding of any given situation. He focused on the salient features for him, but may have missed other opportunities. Information linked to players was often verbalized, unlike information 
associated with shuttle trajectory that was understood through opponent behaviour information.

There were also differences in explained knowledge which were more numerous and more varied when the time available to act was greater. In emergency situations the player made decisions from a limited repertoire, these were based on the salient features about the player himself and rules about the situation. In less time-constrained situations, previous or constructed knowledge was more common and more varied. For the decisions made to influence the opponent's decision, knowledge about the opponents, expectation, action consequence, and rules were used. These results are also consistent with those seen in Macquet's (2001) volleyball study. When time pressure was perceived to be high (for example in a defensive situation), the decision-making of volleyball players proceeded essentially from information. When the available time to act was longer, the players verbalized more knowledge-based decision-making. The difficulties of situation assessment under high temporal pressure are consistent with the idea of sufficient understanding to act in a dynamic situation (Amalberti 2001). Players do not try to understand everything to do with a situation. Instead, they attempt to control their lack of understanding by focusing on salient features that will help them to make the most appropriate decision.

\subsection{Contextual building of the rally}

The results indicated various decisions made during the course of the match. They can be categorized as belonging to different levels. The first can be attributed to player verbalizations of decision-making. The player indicated both his decision and in the technical and tactical gesture how he would build the rally (e.g., to block at the net). The player also noted the expected effects of the situation evolution. This was seen at a very local level. The second 
level related to a desired objective to manipulate the current situation in order, for example, to surprise the opponent. The third level related to intention; the desired decision on the rally evolution, for example, to take advantage during the build up of the rally. Specifically, these levels concerned action, situation or rally. They referred to various time-based events and players did not try to win the rally immediately. They attempted to create progressively good conditions to win by building advantage in the rally. Only when situational conditions were perceived to be right did they try to finish the point. Sometimes they accept a delay in creating winning conditions and maintain the rally. All intentions and decisions showed a contextual building of the rally according to the evolution of the situation. The most common intention was to take the advantage and thus build up the rally. The most common decisions varied between game situations. At service and return of serve, decisions aimed at putting pressure on the opponent. At the third or fourth shot, decisions were more varied. This can be explained by the nature of the situations. At the beginning of the rally, uncertainty is deemed to be low so the player can often impose his play. In the third or fourth shot, the rally is more advanced with each team influencing its evolution. At this stage it appears more difficult for players to impose their game because their decision is a result of the previous and anticipated situations. This study was focused on the temporal-nature of decision-making. Decisions were viewed in a synchronic and a diachronic way. Synchrony concerns the first four shots of the rally; whereas diachrony concerns the period from the third or the fourth shot of one rally to the first shot of the next rally. Therefore, this study proved innovative since prior research has focused only on diachronic decisions during the course of a match. In the present study, the four first shots were verbalized. This allowed greater understanding of the build up of each rally from its beginning, where important decisions were made regarding the development of the rally. 
The results of this study indicated that the same local decision could be used for different aims. For example, the local decision of a cross-court drop referred to the decision to play wide, surprise opponents, and influence an opponent's decision. Therefore, local decisions were perceived as an effective way to reach a goal. They were considered as specific skills from an individual's repertoire.

The decisions elicited from the analysis were similar with the control modes proposed by Hollnagel (1998). According to the situations, the decision to realize a limited choice referred to scrambled control or opportunistic control. A scrambled control occurred when a situation evolved in an unexpected way and when there was very little time to act. Whereas, opportunistic control occurred when the choice of actions was limited due to the constraints in movement, time or space. In contrast to Hollnagel, situations did not appear to be unfamiliar to players; they were simply unexpected. This was different to scrambled control that was typified by a loss of situational awareness with emergency decision-making.

The decision to play wide, to surprise the opponents, to realize a limited choice, and the intention of finish the point, belongs to opportunistic control. In the situation, the decision is made from salient features of the situation instead of stable intentions or goals. In these situations, players were waiting for relevant information to make their decision, such as information linked to the behaviour or the position of their opponents. The decision to ensure his action, to observe the opponent's response to his action, and influence the opponent's decision was based on a tactical control. The decisions were planned. Players used known rules but which were limited to a restricted situational context. These rules could be individual (e.g., to reproduce an action, or to observe an action), collective (e.g., to influence opponent decision) or situational (e.g., to ensure his action). These types of decisions show that all the situations are not ambiguous, ill-defined or unsteady, as has been suggested by the Natural Decision Making Model (e.g. Klein et al. 1993, Zsambok and Klein 1997). Some 
situations can be anticipated and/or easy to understand by the players than some others. The players appear to be rational actors: they use rules that have been overtrained. This use of rules is consistent with McPherson and Kernodle's (2003) results. Nevertheless these situations were not the most frequently reported in the matches studied.

\subsection{Consequences for coaching}

The building of the badminton rally appears to be dynamic and contextual. It is founded on a sufficient understanding of the current situation information from a player's past as well as prediction about the future events. This type of situation is rarely considered during badminton coaching. Instead, players work on skill development and regimented routines. This type of training would seem at odds with the findings of this study. Coaches typically ask players to link action sequences. Consideration of errors within the rally development are rare and the opponents are considered as 'sparing partners' doing little more than helping to develop routines. The findings of this study suggest that routines are not always used as players try to build up the rally by exploiting the opponent's actions, position, and behaviour frequently by employing a surprise effect. If training is focused on routines, the conditions for analysis and to exploit the opponent's game may not be in place. Routine training relies on an ideal player frame; one that is explanatory and prescriptive. During a competitive situation, players frequently use a compromise model. This model suggests that to win the match, there will be occasions when the player must accept a deferral of the win when difficulties of play appear. In easily understandable situations, players will attempt to take the advantage in the rally or to finish the point quickly. In difficult situations, a full understanding of the situation does not exist; information is not available and the mental load is high. In this case the findings of this study would suggest the use of a lower level of understanding, to play by 
routines, for example, in an emergency situation players should lift the shuttle to create more time for decision making and understanding. Understanding will not be optimal, but it allows the player to act with some efficiency in pursuit of the maintenance of the rally. This compromise requires essential knowledge about ones partner and the opponents. This knowledge seems to be built and updated during the match itself. In addition, it is possible that it could be developed during training; a specific framework where the player changes role to become an accomplice for the opponent. The player would use specific techniques to research an opponent's decisions for example, using video analysis of the opponent's strategies. Through theses techniques, the opponent's strategies would become better understood to the player and then increasingly exploited progressively by the player.

\section{Conclusion}

This study aimed to reveal the contextual decision-making of high-level badminton players during competition and to help coaches to understand the preferential mode of player cognitive functioning. Decision-making was shown to depend highly on understanding of the immediate situation. The aim, for coaches, is to increase understanding of the conditions of the situation in order to facilitate performance. The study revealed that taking account of context and previous, current and anticipated events during a rally was essential for understanding and naturalistic decision-making. This study could be continued through a longitudinal approach by consideration of play at different stages of the match and in extended rallies or indeed at different stages of a competitive season. These studies may show further differences in decision-making that depend on the advantage gained during the match and performance-based fluctuations throughout a season. 


\section{Acknowledgments}

This study was supported by a grant from the French Ministry of Youth and Sports. The authors are grateful to the coaches and the athletes of the French national badminton teams for their participation. 


\section{References}

AMALBERTI, R., 1996, La conduite des systèmes à risques [The control of risky systems] (Paris : PUF).

AMALBERTI, R., 2001, La maîtrise des situations dynamiques [Control of dynamic situations], Psychologie Française, 46, 107-118.

AMALBERTI, R., 2003, La sécurité écologique et la maîtrise des situations : concepts et stratégies mis en jeu par les professionnels pour assurer leur propre sécurité et celle du système [Ecological security and situation control : concepts and strategies used by professionals to ensure their own security and those of the context]. In Les risques professionnels : évolutions des approches, nouvelles perspectives, D.R. Kouabenan and M. Dubois (Eds), pp. 73-82 (Toulouse: Octares).

AMALBERTI, R. and HOC, J.-M., 1998, Analyse des activités cognitives en situations dynamiques: pour quels buts ? Comment? [Cognitive activities analysis in dynamic situations : for which goals ? How ?] Le Travail Humain, 61, 209-234.

AMALBERTI, R. and MALATERRE, G., 2001, De l'erreur humaine au risque : évolution des concepts en psycho/ergonomie [From human error to risk : concepts evolution in pyschology/ergonomics]. In Risques et défaillances. Approches interdisciplinaires, R. Amalberti, C. Fusch, and C. Gilbert (Eds), pp. 71-106 (Grenoble: CNRS-MSH, 2001).

CHASE, W.G. and SIMON, H.A., 1973, Perception in chess. Cognitive Psychology, 4, 55-81.

D'ARRIPE-LONGUEVILlE, F., SAURY, J., FOURNIER, J. and DURAND, M., 2001, Coach-athlete interaction during elite archery competitions: an application of methodological framework used in ergonomics research to sport psychology. Journal of Applied Sport Psychology, 13, 275-299. 
DE KEYSER, V., 2003, Les systèmes de report d'incidents [Systems of incidents carried forward]. In Autour de la mesure du risque, R. Amalberti, C. Fuschs and C. Gilbert (Eds) pp. 41-71 (Grenoble : CNRS-MSH).

ENDSLEY, M.R., 1995, Toward a theory of situation awareness in dynamic systems. Human Factors, 37, 32-64.

ENDSLEY, M.R., BOLTE, B. and JONES, D.G., 2003, Designing for situation awareness (London: Taylor and Francis)

ERICSSON, K.A. (1996), The Road to Excellence (Mahwah, NJ: Erlbaum).

FRENCH, K.E. and MAC PHERSON, S.L., 1999, Adaptations in response selection processes used during sport competition with increasing age and expertise, International Journal of Sport Psychology, 30, 173-193.

GIBSON, J.J., 1979, The Ecological Approach to Visual Perception (Boston: Houghton Mifflin).

HAUW, D. and DURAND, M., 2004, Elite athletes' differentiated action in trampolining: a qualitative and situated analysis of different levels of performance using retrospective interviews, Perceptual and Motor Skills, 98, 1139-1152.

HOC, J.-M., 2001, A cognitive approach to cooperation in dynamic situations. International Journal Human Computer Studies, 54, 4, 509-540.

HOC, J.-M. and AMALBERTI, R., 1999, Analyse des activités cognitives en situations dynamiques: d'un cadre théorique à une méthode [Analysis of cognitive activities in dynamic situation : from a theoretical frame to a method]. Le Travail Humain, 62, 97129.

HOLLNAGEL, E., 1998, Cognitive Reliability and Error Analysis Method (London: Elsevier). 
KLEIN, G.H., ORASANU, J. CALDERWOOD, R. and ZSAMBOK, C.E. (Eds), 1993, Decision Making in action: Models and Methods (Norwood, NJ:Ablex).

LAVE, J., 1988, Cognition in Practice (Cambridge: Cambridge University Press).

MACQUET, A.-C., 2001, Le contrôle des situations chez les volleyeurs experts: informations perçues et connaissances mobilisées ou construites [Situation control by expert volley-ball players : informations perceived and knowledge used or constructed]. $\mathrm{PhD}$ thesis, University of Paris XI.

MAC PHERSON, S.L. and KERNODLE, M.W., 2003, Tactics, the neglected attribute of expertise. In Expert Performance in Sports, J.L. Starkes and K.A. Ericsson (Eds), pp. 137-168 (Champaign, IL: Human Kinetics)

PITZ, G.F., 1992, Risk taking, design and training. In Risk-Taking Behavior, J.F. Yates (Ed), pp. 283-320 (Chichester: Wiley).

SANDERS, A.F., 1986, Energical states underlying task performance. In Energetics and Human Information Processing, R.J. Hockey, A.W.K. Gaillard and M.G.H. Coles (Eds), pp. 139-154 (Dordrecht: Nijoff).

SAURY, J., DURAND, M. and THEUREAU, J., 1997, L'action d'un entraîneur expert en voile en situation de compétition: étude de cas [action of expert competition sailing coach: case study]. Science et Motricité, 31, 21-35.

SEVE, C. and DURAND, M., 1999, L'action de l'entraîneur de tennis de table comme action située [Tennis table coach actions like situated actions]. Advante, 5, 69-85.

SEVE, C., SAURY, J., RIA, L. and DURAND, M., 2003, Structure of expert players' activity during competitive interaction in table tennis. Research Quarterly For Exercice and Sport, 74, 71-83.

SIMON, H.A., 1957, Models of Man: Social and Rational. Mathematical Essays on Rational Human Behavior in a Social Setting (New York: Wiley). 
SUCHMAN, L.A., 1987, Plans and Situated Actions (Cambridge: Cambridge University Press).

WICKENS, C, 1992, Workload and situation awareness: an analogy of history and implications. Insight, The HFES Visual Performance Technical Group Newsletter, 14, $1-3$.

VON CRANACH, M. and HARRE, R., 1982, The Analysis of Action. Recent Theoretical and Empirical Advances (Cambridge: Cambridge University Press).

WILLIAMS, M. and DAVID, N. 1995, Knowledge in sport: a by-product of experienced or a caracteristic of expertise? Journal of Sport and Exercice Psychology, 17, 259-275.

ZSAMBOK, C.E. and KLEIN, G. (Eds), 1997, Naturalistic Decision Making (Mahwah, NJ: Erlbaum). 
Figure captions

Figure 1. Decision evolution during the match

Figure 2. Serve decision evolution during the match

Figure 3. Return of serve decision evolution during the match

Figure 4. Third or fourth shot decision evolution during the match 

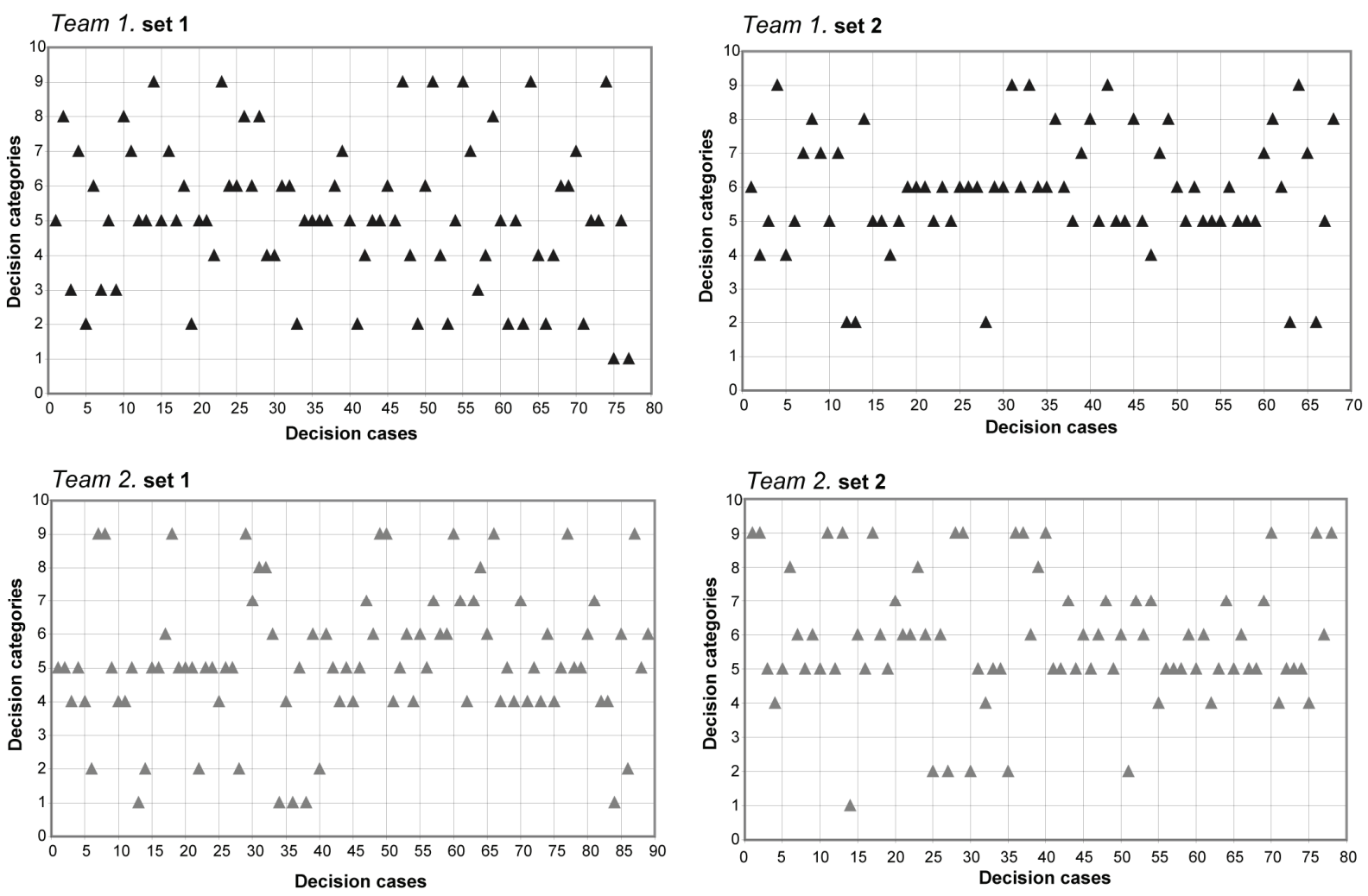

Decision categories: 1 to ensure his action; 2 . to realize a limited choice; 3 to observe opponent response to his own action; 4 to influence opponent decision; 5 to put pressure on opponents; 6 to surprize opponents; 7 to reproduce an efficient action; 8 to play wide; 9 to finish the point. Decisions from 1 to 3 correspond to the intention of maintaining the rally; decisions from 4 to 8 belong to the intention of taking the advantage. 

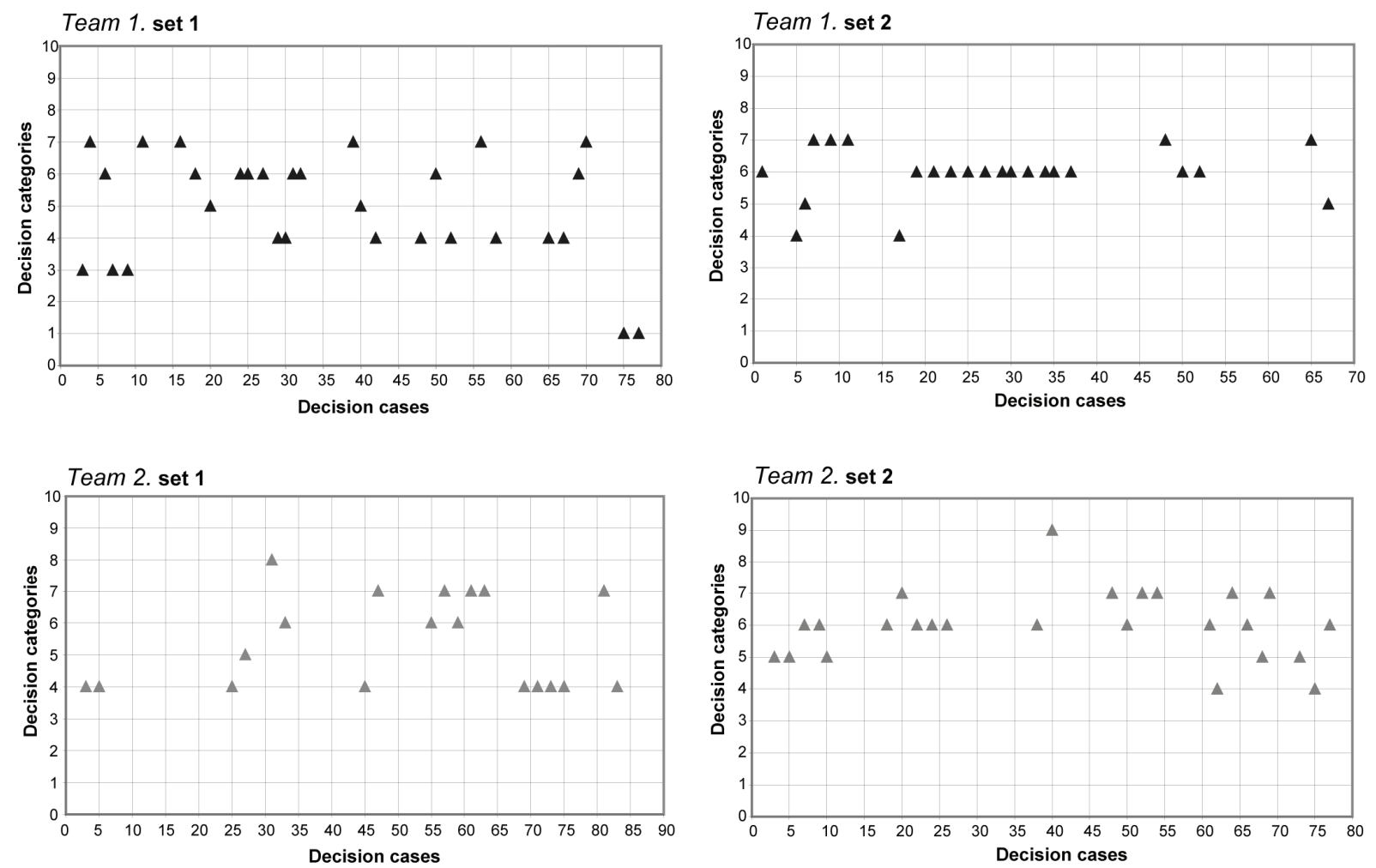

Decision categories: 1 to ensure his action; 2. to realize a limited choice; 3 to observe opponent response to his own action; 4 to influence opponent decision; 5 to put pressure on opponents; 6 to surprise opponents; 7 to reproduce an efficient action; 8 to play wide; 9 to finish the point. Decisions from 1 to 3 correspond to the intention of maintaining the rally; decisions from 4 to 8 belong to the intention of taking the advantage. 

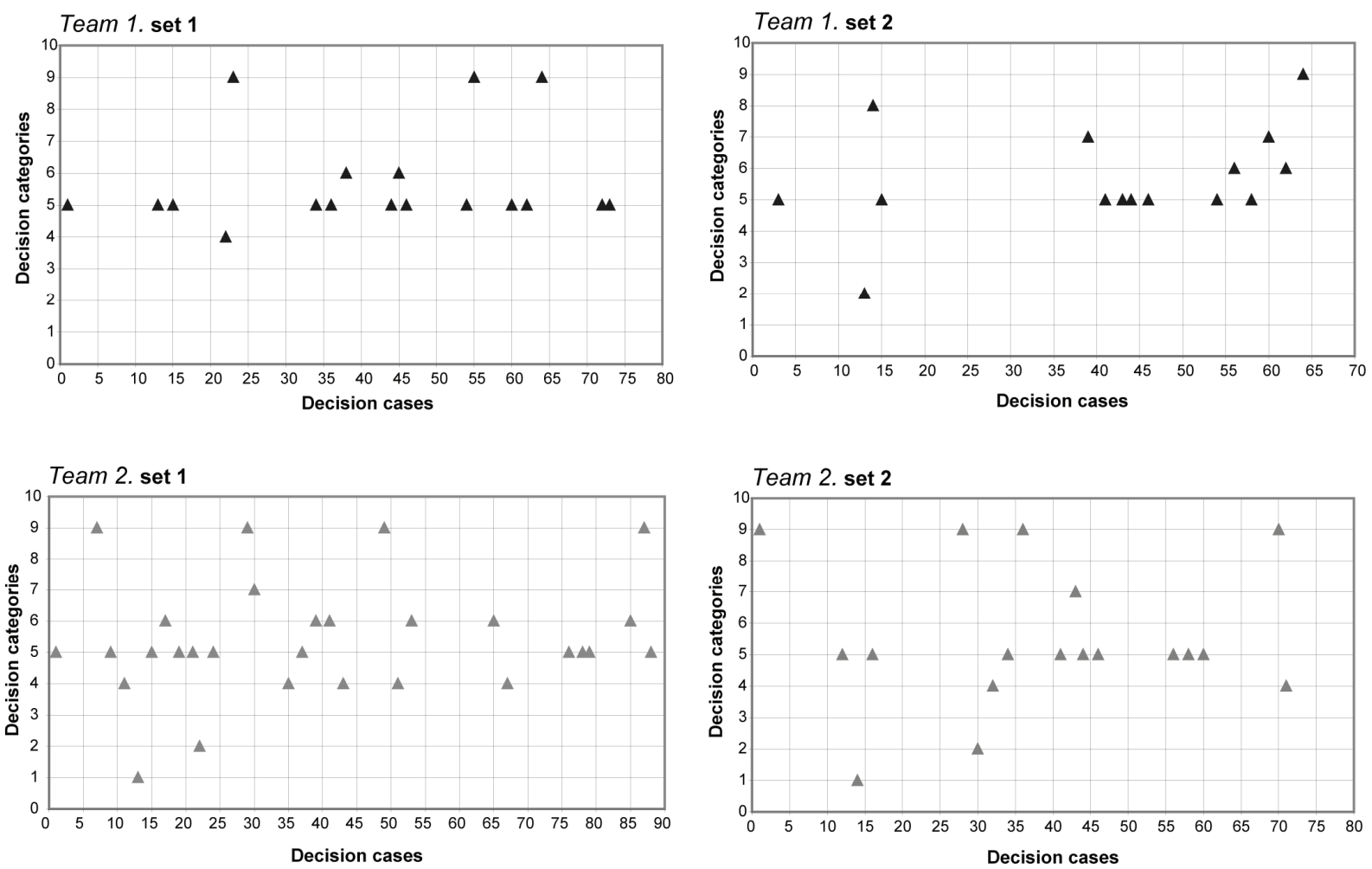

Decision categories: 1 to ensure his action; 2 . to realize a limited choice; 3 to observe opponent response to his own action; 4 to influence opponent decision; 5 to put pressure on opponents; 6 to surprise opponents; 7 to reproduce an efficient action; 8 to play wide; 9 to finish the point. Decisions from 1 to 3 correspond to the intention of maintaining the rally; decisions from 4 to 8 belong to the intention of taking the advantage. 

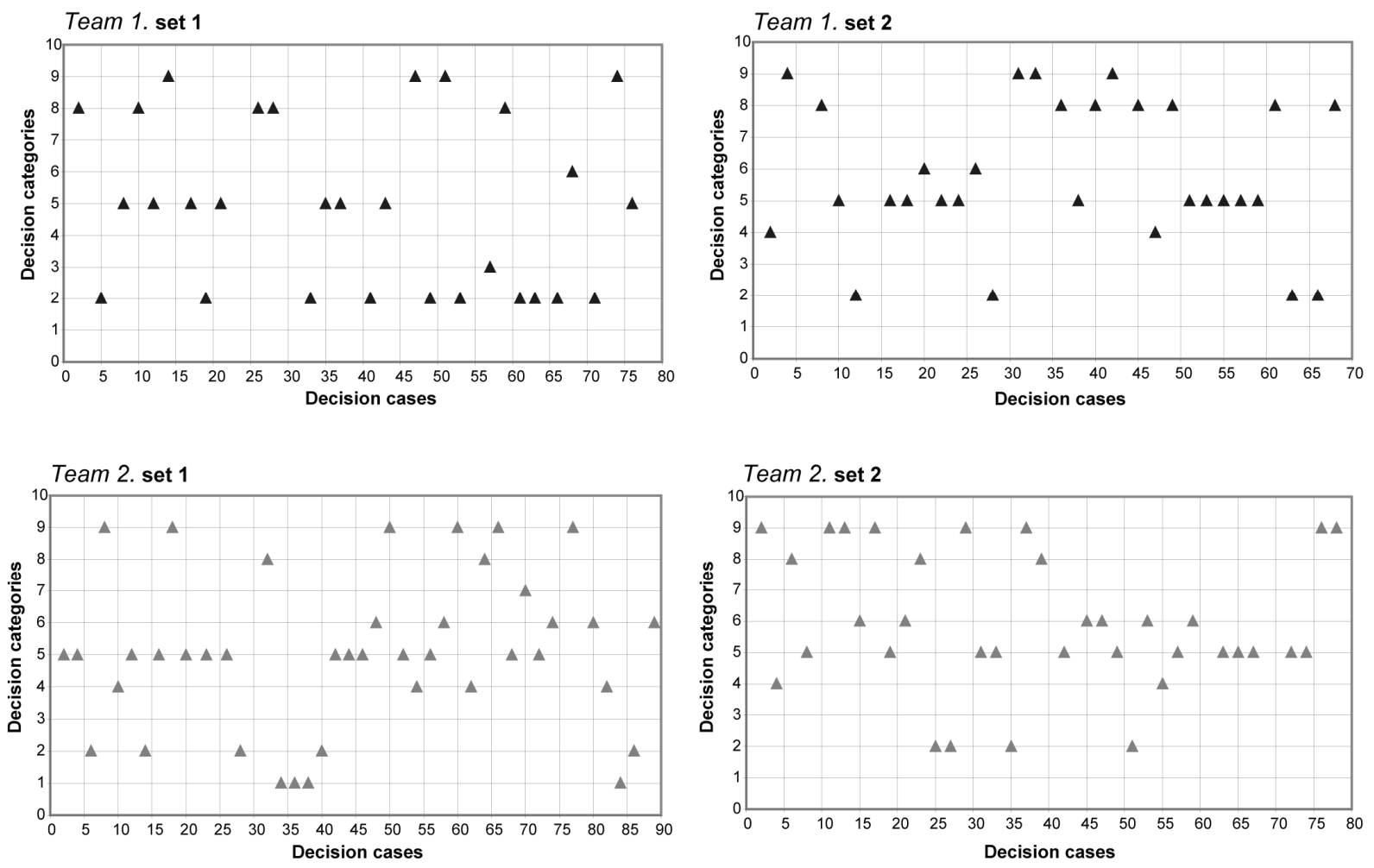

Decision categories: 1 to ensure his action; 2 . to realize a limited choice; 3 to observe opponent response to his own action; 4 to influence opponent decision; 5 to put pressure on opponents; 6 to surprise opponents; 7 to reproduce an efficient action; 8 to play wide; 9 to finish the point. Decisions from 1 to 3 correspond to the intention of maintaining the rally; decisions from 4 to 8 belong to the intention of taking the advantage. 